\title{
IMPLEMENTASI MATERI IPA APLIKATIF BERBASIS KESEHATAN MASYARAKAT BAGI WARGA DUSUN DIRAN, KECAMATAN LENDAH, KULONPROGO
}

\section{THE IMPELEMENTATION OF APPLICATIVE SCIENCE MATERIAL-BASED ON PUBLIC HEALTH FOR PEOPLE IN DIRAN VILLAGE, LENDAH, KULONPROGO}

\author{
Putri Anjarsari*, Wita Setianingsih, Widodo Setiyo Wibowo, dan Allesius Maryanto
}

*Prodi Pendidikan IPA, 085643793136, email: putri_anjarsari@uny.ac.id

\begin{abstract}
Abstrak
Kegiatan PPM ini bertujuan agar warga masyarakat Dusun Diran, Kecamatan Lendah, Kabupaten Kulonprogo dapat memahami pentingnya menjaga kesehatan dan mempraktekkan materi IPA aplikatif berbasis kesehatan masyarakat.

Kegiatan PPM ini dilaksanakan dengan metode pelatihan, dengan langkah-langkah sosialisasi, penyuluhan, dan evaluasi. Khalayak sasaran dalam kegiatan ini adalah warga masyarakat Dusun Diran, Kecamatan Lendah, Kabupaten Kulonprogo. Jumlah peserta yang ikut dalam kegiatan pelatihan adalah 54 orang dari target peserta 25 orang. Selama kegiatan berlangsung para peserta aktif menyimak materi, bertanya, dan praktek untuk menerapkan cara menjaga kesehatan.

Berdasarkan hasil evaluasi kegiatan yang telah dilakukan, diperoleh hasil bahwa warga masyarakat Dusun Diran, Kecamatan Lendah, Kabupaten Kulonprogo dapat memahami pentingnya menjaga kesehatan dan mepraktekkan materi IPA aplikatif berbasis kesehatan masyarakat.
\end{abstract}

Kata kunci: pelatihan, kesehatan, IPA, materi aplikatif

\begin{abstract}
The aim of the PPM are people in Diran Village can be more aware about the importance of health and can aplly the applicative science material-based on public health.

The PPM activities carried out by training, counseling, and evaluation. The subject of this activity were people in Diran village, Kulonprogo. The number of participants were 54 people from the target of 25 people. During the activity, the participants were actively listen to the discussion, ask question, and practice to implement the material.

The result of the activity are some people in Diran village can be more aware about their helath and can apply the applicative science material-based on public health in their daily life.
\end{abstract}

Key words: training, health, applicative science material

\section{PENDAHULUAN}

Lingkungan Dusun Diran, Kecamatan Lendah, Kabupaten Kulonprogo berlokasi di bagian timur Wates. Sebagian besar mata pencaharian penduduknya adalah bertani dan berdagang. Rumah penduduk berada di daerah bukit yang lokasinya jauh dari jalan utama kota. Oleh sebab itu, akses warga untuk mendapatkan fasilitas kesehatan terbatas hanya di puskemas. 
Kegiatan seperti penyuluhan dan pelatihan terkait kesehatan di lokasi Dusun Giri masih sangat jarang dilakukan. Hal ini menyebabkan kurangnya kesadaran masyarakat terhadap kesehatan. Berdasarkan hasil wawancara, warga masyarakat membutuhkan hal itu sebagai pengetahuan untuk menjaga kesehatan untuk menghindari penyakit agar tidak perlu memeriksakan diri ke rumah sakit yang lokasinya cukup jauh dari desa.

Materi terkait kesehatan termasuk dalam materi IPA yang aplikatif. Materi IPA yang dimaksud disini adalah materi yang biasanya diajarkan pada siswa Sekolah Menengah Pertama (SMP), namun bisa juga diajarkan kepada warga masyarakat karena sifatnya yang terapan. Beberapa materi IPA aplikatif diantaranya: zat aditif dan adiktif, pencemaran air, tekanan darah, cacat mata. Materi-materi tersebut sangat disayangkan apabila hanya diajarkan di SMP sebagai materi IPA, sehingga perlu di sosialisasikan kepada warga masyarakat agar dapat digunakan sebagai pengetahuan kesehatan dan tindakan pencegahan penyakit.

IPA berkaitan dengan penyelidikan tentang gejala dan fenomena alam. Sains / IPA pada hakikatnya merupakan cara atau jalan berpikir ( $a$ way of thinking), cara untuk penyelidikan (a way of investigating), kumpulan pengetahuan (a body of knowledge), dan science and its interactions with technology and society ${ }^{[1]}$. Jadi, IPA juga merupakan hasil interaksi antara teknologi dan masyarakat. Supaya interaksi berjalan dinamis, maka masyarakat perlu mengetahui perkembangan IPA terkini. Kegiatan sosialisasi, penyuluhan, dan pelatihan adalah beberapa cara yang dapat dilakukan untuk menyebarluaskan IPA dengan perkembangan terbaru.

Materi IPA yang diajarkan pada siswa SMP dapat diterapkan dalam kehidupan sehari-hari sehingga bersifat aplikatif. Beberapa materi IPA aplikatif adalah zat aditif dan adiktif, pencemaran air, cacat mata. Materi-materi tersebut berkaitan dengan bidang kesehatan. Agar materi tersebut tidak hanya disampaikan sebagai materi di sekolah, maka dirasa perlu dilakukan penyebarluasan materi tersebut melalui kegiatan penyuluhan pada masyarakat supaya kebermaknaan dan kebermanfaatan materi tersebut lebih mendalam. Berikut adalah deskripsi materimateri IPA aplikatif berbasis kesehatan masyarakat.

1. Zat aditif dan Adiktif

Zat aditif adalah zat-zat yang ditambahkan pada makanan selama proses produksi, pengemasan, atau penyimpanan untuk maksud tertentu. Zat aditif makanan adalah bahan yang sengaja ditambahkan pada makanan untuk maksud teknologi (organoleptic) pada pembuatan, penyimpanan, atau pengangkutan makanan untuk menghasilkan komponen yang mempengaruhi sifat khas makanan ${ }^{[5]}$.

Penambahan zat aditif dalam makanan berdasarkan pertimbangan agar mutu dan kestabilan makanan tetap terjaga dan untuk memertahankan nilai gizi makanan yang mungkin rusak atau hilang dalam proses pengolahan. Zat aditif makanan dapat digolongkan menjadi 2, yaitu a) zat aditif sengaja, dan b) zat aditif tidak sengaja ${ }^{[6]}$. Zat aditif dibedakan menjadi zat pewarna, pemanis, pengawet, dan penyedap ${ }^{[2]}$. Pada awalnya zat-zat aditif berasal dari tumbuhan yang selanjutnya disebut dengan zat aditif alami. Umumnya, zat aditif alami tidak menimbulkan efek yang membahayakan bagi kesehatan manusia. Akan tetapi, jumlah yang melebihi batas dapat memacu penyakit seperti kanker.

Penambahan zat aditif makanan seringkali disalahgunakan, yaitu menggunakan bahan yang berbahaya seperti boraks dan formalin. Hal inilah yang mendasari kegiatan penyuluhan ini dilaksanakan.

2. Tekanan Darah

Tekanan darah merupakan salah satu pengukuran yang penting dalam menjaga kesehatan tubuh, karena Tekanan darah yang tinggi atau 
Hipertensi dalam jangka panjang akan menyebabkan perenggangan dinding arteri dan mengakibatkan pecahnya pembuluh darah. Pecahnya pembuluh darah inilah yang menyebabkan terjadinya Stroke. Beberapa penyakit yang diakibatkan oleh Tekanan darah tinggi diantaranya adalah Stroke, Penyakit Jantung, Penyakit Ginjal dan Aneurisma.

Dalam keadaan sehat, tekanan sistol dan diastol seseorang adalah 120/80. Artinya tekanan sistol $=120$ mmHg, sedangkan tekanan diastol 80 mmHg. Perbedaan antara besaranya tekanan sistol dan diastol disebut tekanan denyutan yang rata-ratanya adalah $40 \mathrm{mmHg}{ }^{[8]}$. Nilai tekanan darah yang sehat untuk orang dewasa yang berusia 18 tahun keatas adalah bertekanan sistolik kurang dari $121 \mathrm{mmHg}$. Bila nilai sistoliknya berkisar antara 121 - $139 \mathrm{mmHg}$, maka orang tersebut mengalami Prehypertansion, dimana tekanan darahnya lebih tinggi dari tekanan darah yang dianjurkan. Tekanan darah tinggi (Hypertension) dibagi menjadi dua tahap, yaitu tekanan darah tinggi tahap 1 dan tahap 2. Bila nilai tekanan sistolik berada diantara $140-159 \mathrm{mmHg}$ maka disebut tekanan darah tinggi tahap 1 (Stage 1 Hypertension). Kondisi dimana nilai sistolik lebih tinggi dari $159 \mathrm{mmHg}$ disebut dengan tekanan darah tinggi tahap 2 (Stage 2 Hypertension) [3]. Sedangkan tekanan normal vena bervariasi antara 30-90 $\mathrm{mmHg}$; tekanan vena pada tangan antara $30-40 \mathrm{mmHg}$ [8].

3. Cacat mata

Mata merupakan salah satu contoh alat optik, karena dalam pemakaiannya mata membutuhkan berbagai benda-benda optik seperti lensa. Setidaknya ada tiga jenis cacat mata yang diakibatkan oleh kemampuan daya akomodasinya yaitu: miopia, hipermetropia dan presbiopia. Berikut ini adalah gambar masing-masing cacat mata dan jangkauan penglihatannya.

a. Mata normal (Emetropia) : memiliki titik jauh (PR) pada jarak jauh tak berhingga dan titik dekat $(\mathrm{PP})=25$ $\mathrm{cm}$, mata ini jangkauan penglihatannya paling lebar.

b. Rabun jauh (Miopia) : memiliki titik jauh (PR) terbatas/kurang dari tak berhingga dan titik dekat $(\mathrm{PP})=25$ $\mathrm{cm}$. Rabun jauh atau miopi merupakan cacat mata yang terjadi karena lensa mata tidak dapat memipih sebagaimana mestinya ${ }^{[4]}$.

c. Rabun dekat (Hipermetropia) : titik dekat mata orang yang menderita rabun dekat lebih jauh dari jarak baca normal (PP > $25 \mathrm{~cm}$ ). Rabun dekat atau hipermetropi merupakan cacat mata yang terjadi karena lensa mata tidak dapat mencembung sebagaimana mestinya. Akibatnya, berkas cahaya dari objek terfokus dan membentuk bayangan di belakang retina ${ }^{[7]}$.

d. Rabun jauh dan dekat (Presbiopia) : memiliki titik jauh (PR) kurang dari tak berhingga dan titik dekat (PP) > $25 \mathrm{~cm}$, cacat mata ini merupakan gabungan dari hipermetropi dan miopi, sering disebut sebagai cacat mata tua.

e. Gloukoma

Glaukoma merupakan kelainan mata yang dicirikan dengan rusaknya saraf optik yang berfungsi untuk membawa pesan-pesan cahaya dari mata ke otak. Kerusakan saraf optik ini disebabkan oleh kelebihan cairan humor yang mengisi bagian dalam bola mata. Cairan mata yang diproduksi oleh jaringan-jaringan di depan bola mata ini sebenarnya berfungsi untuk membawa makanan untuk kornea dan lensa mata.

f. Astigmatis

Astimatis adalah ketidakteraturan lengkung-lengkung permukaan bias mata yang berakibat tidak terpusatkannya sinar cahaya pada 
satu titik di selaput jala (retina) mata. Ada dua jenis astigmatis, yaitu astigmatis kornea yang disebabkan oleh ketidakteraturan lengkung atau daya bias kornea dan astigmatis lensa akibat ketidakteraturan daya bias lensa mata. Astigmatis menyebabkan penderitanya mengalami kesulitan melihat sesuatu secara jelas atau menjadi kabur, terutama untuk obyek-obyek yang berukuran kecil. Astigmatis yang umumnya diderita oleh penyandang miopia ini biasanya dapat dikoreksi dengan kacamata berlensa silindris atau lensa kontak. Dapat juga dilakukan operasi refraktif.

Berdasarkan hasil analisis situasi, maka dapat diidentifikasi beberapa permasalahan yang muncul di masyarakat khususnya warga masyarakat Dusun Diran, Kecamatan Lendah, Kabupaten Kulonprogo

1) Kesadaran masyarakat untuk menjaga kesehatan masih kurang.

2) Kegiatan penyuluhan kesehatan masih sangat jarang dilakukan di Dusun Diran, Kecamatan Lendah, Kabupaten Kulonprogo.

Berdasarkan identifikasi masalah, permasalahan dalam kegiatan ini dirumuskan sebagai berikut: "Bagaimana memperkaya pemahaman dan meningkatkan kesadaran warga masyarakat Dusun Diran, Kecamatan Lendah, Kabupaten Kulonprogo untuk menjaga kesehatan?"

\section{SOLUSI/TEKNOLOGI}

Solusi diterapkan untuk menjawab rumusan masalah tersebut adalah melalui kegiatan pelatihan. Pelatihan ini bertujuan agar warga masyarakat Dusun Diran, Kecamatan Lendah, Kabupaten Kulonprogo dapat memahami pentingnya menjaga kesehatan dan mempraktekkan materi IPA aplikatif berbasis kesehatan masyarakat. Khalayak sasaran kegiatan pelatihan ini adalah warga masyarakat Dusun Diran, Kecamatan Lendah, Kabupaten Kulon Progo. Kegiatan PPM yang dilaksanakan berupa penyuluhan, dengan langkah-langkah sosialisasi, penyuluhan, dan evaluasi. Evaluasi kegiatan dilakukan melalui evaluasi proses dan hasil. Evaluasi proses digunakan untuk menilai keberhasilan proses pelatihan melalui kegiatan observasi, sedangkan evaluasi hasil dilakukan untuk menilai produk penyuluhan berupa kemampuan dan keterampilan menjaga kesehatan.

\section{HASIL DAN DISKUSI}

Lingkungan Dusun Diran, Kecamatan Lendah, Kulon Progo berlokasi di bagian timur Wates. Akses warga untuk mendapatkan fasilitas kesehatan hanya terbatas di Puskesmas. Kegiatan penyuluhan dan pelatihan juga masih sangat jarang dilakukan. Hal tersebut mengakibatkan kurangnya kesadaran masyarakat terhadap kesehatan. Hal itu didukung oleh hasil wawancara kepada warga masyarakat Diran, yang sebagain besar warga masyarakatnya menyatakan membutuhkan penyuluhan/pelatihan sebagai pengetahuan untuk menjaga kesehatan. Kegiatan penyuluhan/pelatihan mengangkat materi yang sebenarnya sudah sering diajarkan pada siswa SMP, yaitu materi IPA aplikatif, terdiri dari zat aditif, cacat mata, dan tekanan darah. Harapannya, salah satu manfaat dari kegiatan penyuluhan/pelatihan ini adalah materi IPA tersebut lebih bermakna dan bermanfaat apabila diajarkan ke masyarakat luas.

Berdasarkan masalah yang telah disampaikan sebelumnya, maka rumusan masalah dalam kegiatan PPM ini adalah "bagaimana cara untuk memperkaya pemahaman dan kesadaran warga masyarakat Dusun Diran, Kecamatan Lendah, Kulonprogo untuk menjaga keseharan". Sehingga tujuan dari kegiatan ini adalah warga masyarakat Dusun Diran, Kecamatan Lendah, Kulon Progo dapat memahami pentingnya menjaga kesehatan 
dan mempraktekkan materi IPA aplikatif berbasis kesehatan masyarakat.

Kegiatan pelatihan ini diikuti oleh warga masyarakat Dusun Diran, Kecamatan Lendah, Kulonprogo. Target peserta pelatihan adalah 25 orang, namun peserta yang datang melebihi target sejumlah 54 orang. Kegiatan pengabdian diawali dengan observasi dan wawancara kondisi di lokasi yang akan dijadikan lokasi PPM, kemudian melakukan sosialisasi terkait kegiatan yang akan dilakukan, setelah itu melakukan penyuluhan, dan terakhir evaluasi. Kegiatan observasi dan wawancara dilakukan pada bulan Mei 2016 untuk memastikan kondisi dan permasalahan yang ada di lapangan. Kegiatan sosialisasi secara singkat dilaksanakan pada akhir bulan september 2016. Dalam kegiatan sosialisasi dipaparkan mengenai pentingnya menjaga kesehatan. Dalam sosialisasi juga disampaikan akan adanya kegiatan penyuluhan yang akan dilaksanakan pada hari minggu, tanggal 2 Oktober 2016. Kegiatan tersebut dilanjutkan dengan pelatihan melalui pemaparan materi dari dosen pendidikan IPA dan kegiatan diskusi. Materi yang disampaikan diantaranya materi zat aditif, materi tekanan darah, dan materi kesehatan mata. Proses selama kegiatan berlangsung, keaktifan peserta, dan kemampuan peserta dalam menjawab serta mempraktekkan bagaimana cara menjaga kesehatan dijadikan dasar evaluasi kegiatan. Kegiatan ini menghasilkan keluaran (output) berupa pemahaman warga masyarakat tentang zat aditif berbahaya, cacat mata, dan tekanan darah tinggi beserta pencegahannya.

$$
\text { Berdasarkan hasil evaluasi }
$$

pelaksanaan kegiatan, dapat dinyatakan bahwa kegiatan pelatihan berhasil mencapai tujuan yang diharapkan. Kegiatan ini telah mampu memberikan kesadaran masyarakat tentang pentingnya menjaga kesehatan dan mempraktekkan materi yang didapatkannya dalam kehidupan sehari-hari. Selama kegiatan pelatihan berlangsung, seluruh peserta tampak aktif menyimak materi yang disajikan. Para peserta juga terlihat antusias ketika diberi kesempatan bertanya dan diberi kesempatan untuk mencoba/mempraktekkan. Peserta juga mampu menjawab pertanyaan-pertanyaan yang diberikan untuk mengetes pemahaman peserta.

Keberhasilan kegiatan pengabdian tidak luput dari faktor-faktor yang mendukung terlaksananya kegiatan. Faktor tersebut antara lain antusiasme warga / peserta dalam mengikuti pelatihan. Hal ini terlihat dari jumlah peserta yang mengikuti pelatihan melebihi target, yaitu 54 orang (dari target awal 25 orang). Selain ini, kegiatan pengabdian berhasil dilaksanakan karena adanya kesesuaian materi pelatihan dengan kebutuhan warga masyarakat. Hal ini menjadikan motivasi tersendiri bagi warga untuk mengikuti pelatihan.

Faktor penghambat kegiatan ini adalah rentang usia peserta yang cukup jauh, sehingga jika diadakan pelatihan lagi, perlu dipertimbangkan peserta yang ikut adalah peserta dengan usia produktif. Mengingat respon positif dari khalayak sasaran, maka perlu dilaksanakan kegiatan lanjutan yang disesuaikan dengan kebutuhan masyarakat untuk menyebarluaskan pengetahuan, dan harapannya dapat lebih meningkatkan kesejahteraan warga masyarakat.

\section{KESIMPULAN}

Warga masyarakat Dusun Diran, Kecamatan Lendah, Kabupaten Kulonprogo dapat memahami pentingnya menjaga kesehatan dan mempraktekkan materi IPA aplikatif berbasis kesehatan masyarakat.

\section{UCAPAN TERIMA KASIH}

Terimakasih pengabdi ucapkan untuk warga Dusun Diran, Kecamatan Lendah, Kabupaten Kulonprogo sehingga kegiatan pengabdian ini dapat terlaksana dengan baik. 


\section{PUSTAKA}

Chiappetta, E. L. \& Koballa, T. R. Jr. (2010). Science instruction in the middle and secondary schoo ( $7^{\text {th }} e d$.). New York: Pearson Education, Inc.

F.G. Winarno. 1992. Kimia Pangan dan Gizi. Jakarta: GramediaPeraturan Menteri Kesehatan RI No.722/Menkes/PER/88

Kumboyono, 2012. Tekanan Darah Arteri. http://ejournal.undip.ac.id/index.php/ medianers/article/download/702/pdf. diakses pada 24 Oktober 2013

Liorente, L. 2004. Myopic versus Hyperopic Eyes: Axial Length, Corneal Shape and Optical Aberrations. Journal of Vision. Vol.4 (5): 288-298.

Peraturan Menteri Kesehatan RI No.722/Menkes/PER/88
Regina Tutik Padmaningrum. 2009. Makalah Program Pengabdian pada Masyarakat Materi Bahan Aditif dalam Makanan. Makalah disampaikan pada kegiatan "Pendidikan dan Pelatihan Kesalahan Konsep dalam Materi IPA Terpadu bagi Guru IPA SMP di Kabupaten Bantul". Diakses pada tanggal 1 Oktober 2015. Dari http://staff.uny.ac.id

Serway, R. A dan Jewett, J. W. 2008. Physics for Scientists and Engineers with Modern Physics. United States of America: Thomson Learning, Inc.

Soewolo, dkk. 2005. Fisiologi Manusia. Malang: UMPress 